\title{
INFILTRAÇÃO MARGINAL DE AGENTES CIMENTANTES EM COROAS METÁLICAS FUNDIDAS
}

\author{
MARGINAL MICROLEAKAGE OF CAST METAL \\ CROWNS LUTING AGENTS
}

\author{
Tomie Nakakuki de CAMPOS* \\ Matsuyoshi MORI* \\ Alberto Tsutomu HENMI** \\ Tetsuo SAITO***
}

\begin{abstract}
CAMPOS, T. N.; MORI, M.; HENMI, A. T.; SAITO, T. Infiltração marginal de agentes cimentantes em coroas metálicas fundidas. Rev Odontol Univ São Paulo, v. 13, n. 4, p. 357-362, out./dez. 1999.

Um dos principais objetivos do cimento, que fixa a restauração protética ao dente, é o selamento da fenda existente entre os mesmos. Para avaliar a infiltração marginal, foram feitos preparos cavitários padronizados, em 20 dentes naturais extraídos. As coroas totais foram fundidas em $\mathrm{NiCr}$, sendo 10 cimentadas com cimento de fosfato de zinco e 10 com cimento resinoso Panavia 21. As amostras foram submetidas à ciclagem térmica e em seguida foram colocadas em solução de azul de metileno a $0,5 \%$. Após o seccionamento vestíbulo-lingual, os corpos-de-prova foram examinados com lupa de aumento. Houve diferença significante entre os dois cimentos testados, sendo que $100 \%$ das amostras cimentadas com cimento de fosfato de zinco apresentaram infiltração atingindo dentina e polpa e 100\% das amostras cimentadas com Panavia 21 não sofreram qualquer tipo de infiltração. Conclui-se que: o cimento resinoso Panavia 21 apresentou melhores resultados, quanto ao grau de infiltração, quando comparado com o cimento de fosfato de zinco, na cimentação de coroas metálicas fundidas em $\mathrm{NiCr}$.
\end{abstract}

UNITERMOS: Infiltração dentária; Cimentação; Coroas.

\section{INTRODUÇÃO}

Os cimentos dentários são utilizados para uma grande variedade de propósitos, sendo uma delas a cimentação de coroas metálicas fundidas em dentes preparados, com a finalidade de selar a fenda existente entre o dente e a coroa metálica correspondente, além de aumentar sua fixação ao dente preparado.

O cimento é definido como uma substância que une duas superficies. Na odontologia, o cimento presta-se não somente como um agente de cimentação, mas também, como isolante térmico, elétrico e químico para o dente em questão.

Como é quase impossivel fechar a interface entre a coroa metálica fundida e a superficie do esmalte dental, haverá sempre uma linha delgada de cimento exposta aos fluidos bucais, ao nível das margens da restauração. É provável que a solubilização do cimento constitua-se no principal fator para a infiltração marginal e o conseqüente aparecimento de cáries secundárias sob as coroas metálicas fundidas ${ }^{8}$.

O cimento de fosfato de zinco é o mais antigo e popular cimento odontológico e sua formulação permanece semelhante àquela introduzida há mais de um século ${ }^{1,3}$. Ainda hoje, o cimento de fosfato de zinco é o mais utilizado na cimentação de coroas, visto que apresenta baixo custo, facilidade de trabalho e boas propriedades mecânicas, porém, é um cimento crítico quanto à solubilização em meio bucal.

Os cimentos resinosos convencionais tiveram seu uso limitado na cimentação de coroas e próte-

\footnotetext{
* Professores Doutores; ${ }^{* *}$ Professor Titular - Departamento de Prótese da Faculdade de Odontologia da Universidade de São Paulo.

** Aluno Bolsista PIBIC-CNPq-USP.
} 
CAMPOS, T. N.; MORI, M; HENMI, A. T.; SAITO, T. Infiltração marginal de agentes cimentantes em coroas metálicas fundidas. Rev Odontol Univ São Paulo, v. 13, n. 4, p. 357-362, out./dez. 1999.

ses parciais fixas devido a problemas inerentes ao material, como maior espessura de película, pouco tempo de trabalho, irritação à polpa e dificuldade de remoção de excessos nas margens ${ }^{6,10}$.

Com o desenvolvimento tecnológico, alguns desses problemas foram resolvidos. Assim, o cimento resinoso adesivo Panavia Ex (Kuraray Co., Ltd.; Osaka, Japan) possui um grupo éster fosfatado adicionado ao monômero, que é responsável pela adesão química não só à estrutura dental, mas também a diversos metais ${ }^{7}$. Dentre suas propriedades salienta-se: uma fina película de $19 \mu \mathrm{m}$, resistência à compressão de quase o dobro suportada pelo cimento fosfato de zinco, além de ser praticamente insolúvel em fluidos bucais. Sua polimerização é anaeróbica, sendo retardada pela presença de oxigênio, o que facilita a remoção dos excessos após o assentamento da peça. Estas características, juntamente com suas demais propriedades mecânicas, tornaram este cimento recomendável para a cimentação de coroas metálicas fundidas ${ }^{11}$. Recentemente, com a introdução de um primer, que antecede a aplicação do cimento, e um novo sistema pasta-a-pasta, surgiu o cimento Panavia 21.

TJAN et al. ${ }^{12}$ (1992) compararam a microinfiltração de coroas totais metálicas em ouro, cimentadas com os cimentos Panavia Ex e fosfato de zinco. Investigaram também o efeito da imersão em água dos corpos-de-prova em 30 e 90 dias. Os achados deste estudo indicaram que as coroas cimentadas com o Panavia Ex exibiram substancialmente menos infiltração marginal que com o fosfato de zinco. Nenhuma diferença significante foi observada entre 30 e 90 dias de imersão em água nas coroas cimentadas com o Panavia Ex.

WHITE et al. ${ }^{14}$ (1992) estudaram a microinfiltração de cimentos convencionais e do Panavia Ex. Realizaram preparos padronizados em 42 dentes recém-extraídos. Seis tipos de cimento foram testados: 1 . cimento policarboxilato de zinco; 2 . fosfato de zinco; 3. ionômero de vidro; 4. Den-Mat "thin film"; 5. Panavia Ex; 6. Den-Mat "thin film" com Tenure. Os grupos que apresentaram a menor infiltração foram os dois últimos grupos.

Visto a importância da infiltração marginal presente nas coroas metálicas fundidas cimentadas, este trabalho tem como objetivo comparar o grau de infiltração, observando a direção dentino-pulpar, utilizando-se o cimento resinoso Panavia 21 e o cimento de fosfato de zinco, na cimentação de coroas metálicas fundidas em $\mathrm{NiCr}$.

\section{MATERIAL E MÉTODOS}

Para o presente trabalho, foram selecionados 20 dentes naturais (caninos e pré-molares) livres de cárie e isentos de esmalte defeituoso ou trincado.

Estes foram obtidos em várias clínicas dentárias, onde foram extraídos por razões diversas, mas principalmente por problemas periodontais. Todos os dentes selecionados foram armazenados em soro fisiológico a $0,9 \%$, com o intuito de não favorecer a desidratação, evitando a deterioração do colágeno da dentina, que tem importância fundamental para o sistema de adesivo testado.

Para o preparo dental, os dentes foram incluídos em cilindros de PVC de $1 / 2$ " e preenchidos com resina acrilica quimicamente ativada (Clássico Artigos Odontológicos Ltda.). Foram realizados preparos para coroa total com instrumento cortante rotatório diamantado $\mathrm{n}^{\circ} 3228$ (KG Sorensen) em alta rotação, sob refrigeração a água para evitar o superaquecimento e as fraturas do dente. Os preparos foram executados segundo a técnica preconizada por SAITO $^{9}$ (1989), com desgastes de 1 a $1,5 \mathrm{~mm}$ na face oclusal e de 0,5 a $1 \mathrm{~mm}$ nas faces axiais. O término cervical selecionado foi de chanfro.

A moldagem foi realizada com silicona de condensação (Optosil-Xantopren, Heraeus Kulzer), aplicando-se a técnica de dupla moldagem. Para conter o material, foram utilizados anéis de cobre (Ewang, São Paulo), que foram perfurados, servindo como moldeiras.

Obteve-se para cada dente preparado um troquel de gesso pedra (Velmix, Sibron Kerr Ind. e Com.), com alívio, obtido pela aplicação de uma camada de cianoacrilato de etila (Super-Bonder, Loctite - S. Paulo), a $1 \mathrm{~mm}$ aquém do término do preparo.

Para a confecção dos padrões de cera, iniciou-se a ceroplastia das coroas a partir das margens do preparo e a seguir, ao redor de todas as paredes do preparo, com a espessura de $0,4 \mathrm{~mm}$.

Os padrões de cera foram incluídos e fundidos com liga de $\mathrm{NiCr}$ (Durabond MS). Em seguida, as coroas foram usinadas e o ajuste de adaptação foi obtido, utilizando-se a silicona fluida (Xantopren), que evidenciou as áreas de contato internos. $\mathrm{O}$ 
CAMPOS, T. N.; MORI, M; HENMI, A. T.; SAITO, T. Infiltração marginal de agentes cimentantes em coroas metálicas fundidas. Rev Odontol Univ São Paulo, v. 13, n. 4, p. 357-362, out./dez. 1999.

ajuste foi realizado até alcançar-se uma adaptação clinicamente aceitável, verificada com sonda exploradora $\mathrm{n}^{\circ} 5$ e lupa de 4 vezes. As coroas foram jateadas com óxido de alumínio de $50 \mathrm{~mm}$.

Antes das cimentações, todos os dentes foram lavados com tergensol (Inodon, Porto Alegre) e recolocados em soro fisiológico até o momento da cimentação. As coroas foram lavadas com éter sulfúrico e secas com jatos de ar.

Para a cimentação, os corpos-de-prova foram divididos em dois grupos:

- Grupo I: Amostras de 1 a 10 para a cimentação com o cimento de fosfato de zinco (S.S. White Artigos Dentários Ltda., Rio de Janeiro).

- Grupo II: Amostras de 11 a 20 para a cimentação com o cimento resinoso Panavia 21 (Kuraray Co., Japão).

A manipulação dos cimentos foi desenvolvida seguindo as recomendações do fabricante. Fez-se o assentamento das coroas com pressão digital e, a seguir, o conjunto foi levado a um dispositivo que mantinha uma pressão constante, com um peso de $6 \mathrm{~kg}$ por 10 minutos.

A fase de ciclagem térmica é um método de pesquisa in vitro que propicia o envelhecimento dos materiais utilizados. Dessa forma, avaliam-se os efeitos das diferenças entre os coeficientes de expansão térmica/contração do material restaurador e da estrutura dental (BOWEN et al. ${ }^{2}, 1982$ ).

Nesta fase, utilizou-se uma máquina de ciclagem térmica desenvolvida no Departamento de Materiais Dentários da FOUSP. Todos os corpos-de-prova foram colocados num compartimento móvel da máquina, que movimentava-se automaticamente entre os dois banhos de $5^{\circ} \mathrm{C}$ e $55^{\circ} \mathrm{C}$, com o tempo de transferência de três segundos entre eles, sendo que ficaram imersos durante um minuto em cada banho. Foram feitos 700 ciclos completos.

Após a fase de ciclagem térmica, os dentes foram secos e aplicou-se duas camadas de cianocrilato de etila em toda raiz do dente, exceto a região próxima à borda da coroa.

Os corpos-de-prova foram colocados numa solução de 0,5\% de azul de metileno por 4 horas. Em seguida foram lavados e secados com papel absorvente.

Os dentes foram seccionados no sentido vestíbulo-lingual com discos de óxido de alumínio montados em mandril para peça de mão. Em seguida foram desgastados com discos de lixa para se obter uma superficie lisa e polida. Uma das metades foi escolhida para a leitura.

A avaliação dos resultados foi feita através da visualização dos corpos-de-prova com lupa de aumento de 4 vezes. Os cortes foram avaliados por três examinadores, seguindo a escala:

- 0 - sem microinfiltração;

- 1 - presença de infiltração até o limite amelodentinário;

- 2 - presença de infiltração até dentina;

- 3 - presença de infiltração atingindo dentina e polpa.

Determinou-se o grau de infiltração, confrontando-se as avaliações de cada examinador. O resultado que mais predominou para cada corpo-de-prova foi considerado o grau de infiltração final.

\section{RESULTADOS E DISCUSSÃO}

A Tabela 1 mostra os resultados finais referentes ao grau de infiltração dos corpos-de-prova.

O selamento marginal é um requisito relevante da prótese fixa, pois, a solução de continuidade entre a restauração e o dente permite o ingresso de bactérias e de suas toxinas, podendo culminar com a destruição do remanescente dentário e causar danos pulpares. A qualidade deste selamento marginal depende das propriedades do agente cimentante, que entre outras características, idealmente, deveria ser insolúvel e aderente às estruturas, que está unindo.

No entanto, ainda não surgiu um agente cimentante completo, com todas as propriedades fisico-químicas e biológicas desejáveis e que pudesse ser utilizado em todos os casos.

Alguns pesquisadores têm-se dedicado ao estudo da microinfiltração entre os diferentes sistemas de cimentação. Porém, às vezes, torna-se difícil a comparação dos resultados, devido as diferentes metodologias e materiais empregados.

Nesta pesquisa, utilizando o cimento Panavia 21, nenhum dos corpos-de-prova apresentou

TABELA 1 - Resultado final do grau de infiltração (número de corpos-de-prova).

\begin{tabular}{l|c|c|c|c|c}
\hline \hline \multicolumn{1}{c|}{ Grupo } & Grau 0 & Grau 1 & Grau 2 & Grau 3 & Total \\
\hline Fosfato de zinco & 0 & 0 & 0 & 10 & 10 \\
\hline Panavia 21 & 10 & 0 & 0 & 0 & 10 \\
\hline \hline
\end{tabular}


infiltração, contrastando com os resultados de outros autores. TJAN et al. ${ }^{12}$ (1992) verificaram que o cimento Panavia Ex apresentou pequeno grau de infiltração entre o metal e o cimento, todavia, empregou coroas áuricas, e sabe-se que este tipo de cimento requer um tratamento especial para as ligas áuricas, tipo estanização, a fim de conferir me-
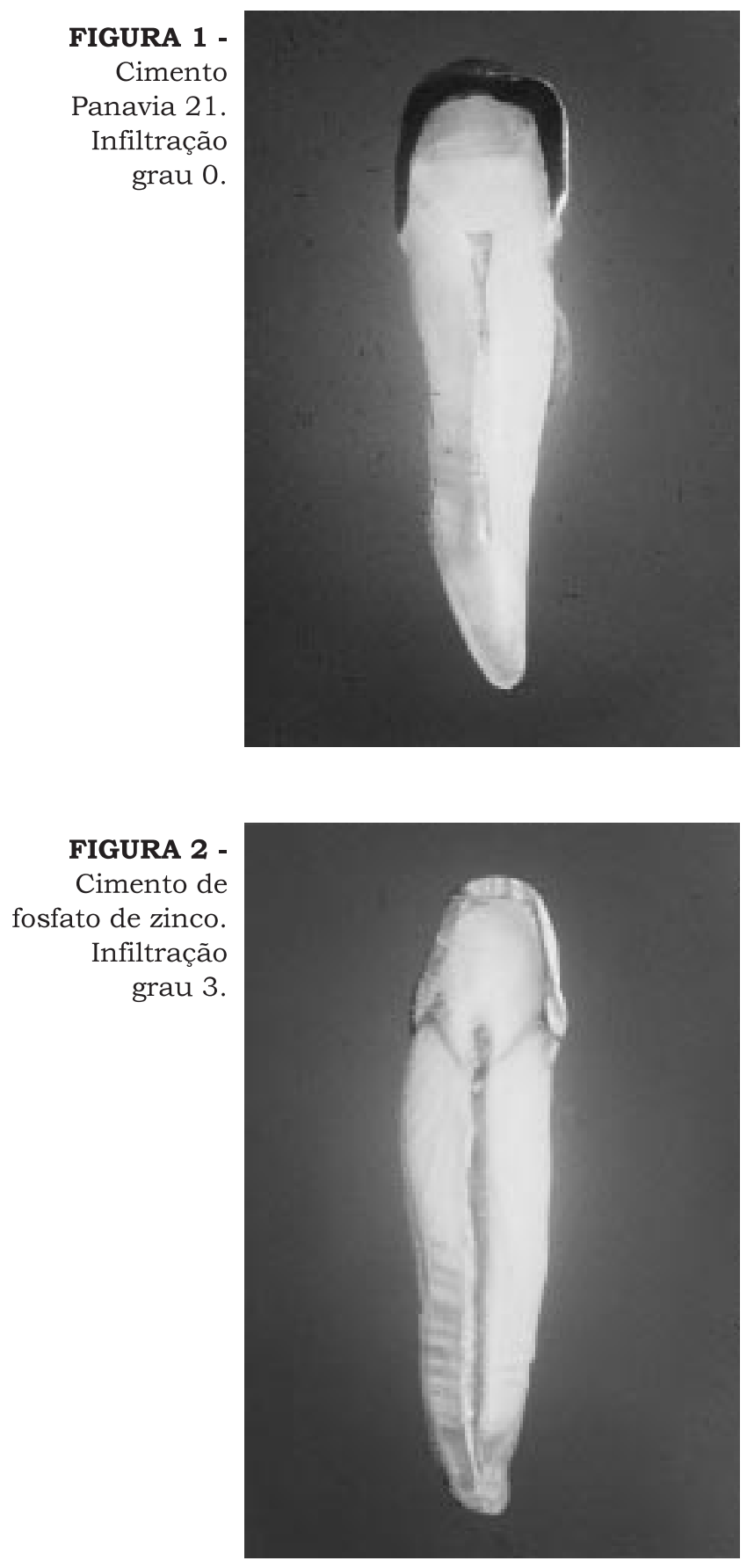

lhor adesão ao metal. WHITE et al. ${ }^{14}$ (1992) também pesquisaram o cimento resinoso Panavia Ex, executando preparos dentários com términos ao nível do esmalte, dentina e cemento. Apesar destes tecidos apresentarem diferentes graus de permeabilidade, os autores concluíram, genericamente, que o cimento Panavia Ex mostrou um certo grau de infiltração.

$\mathrm{Na}$ presente pesquisa, os preparos foram feitos ao nivel do esmalte, para que a permeabilidade da dentina ou do cemento não mascarasse os resultados.

Além disso, utilizou-se o cimento resinoso $\mathrm{Pa}-$ navia 21, que difere do cimento Panavia Ex. Todos os trabalhos consultados na literatura, que utilizaram o cimento Panavia Ex, exibiram algum grau de infiltração. Uma das desvantagens deste cimento é a contração de polimerização, inerente ao material. Segundo HEGDAHL; GJERDET ${ }^{4}$ (1977), as forças geradas pela contração de polimerização destacam a resina das paredes cavitárias e destroem a união resina/dentina, possibilitando a infiltração. $O$ aprimoramento desta resina, com a introdução de um "primer", possibilitou uma união resina/dentina mais resistente e talvez este fator também tenha contribuído para que, neste experimento, não se observasse infiltração, em nenhum dos corpos-de-prova cimentados com Panavia 21 (Figura 1$)$.

Em relação ao cimento de fosfato de zinco, todos os corpos-de-prova apresentaram alto grau de infiltração, concordando com os achados de outros pesquisadores, como TJAN et al. ${ }^{12}$ (1992) e WHITE et al. ${ }^{13}$ (1994). Nenhuma surpresa, pois, sabe-se que uma das desvantagens do cimento de fosfato de zinco é a sua solubilização em meio aquoso. Entretanto, analisando os trabalhos citados na revisão da literatura, notou-se que os estudos avaliavam a infiltração marginal no sentido longitudinal da parede axial. Este é um dado importante quando se quer relacionar a infiltração marginal com a retenção da restauração protética. Contudo, dada a importância da penetração bacteriana e de suas toxinas, em relação ao tecido pulpar, procurou-se, nesta pesquisa, avaliar o grau de infiltração marginal, partindo do esmalte em direção à polpa.

Neste sentido, uma observação importante foi que todos os corpos-de-prova cimentados com cimento de fosfato de zinco alcançaram grau 3, isto 
CAMPOS, T. N.; MORI, M; HENMI, A. T.; SAITO, T. Infiltração marginal de agentes cimentantes em coroas metálicas fundidas. Rev Odontol Univ São Paulo, v. 13, n. 4, p. 357-362, out./dez. 1999.

é, a infiltração do corante atingiu dentina e polpa (Figura 2). Clinicamente, poder-se-ia explicar os processos dolorosos, que ocorrem, às vezes, algum tempo após a cimentação definitiva da restauração protética.

Visto que as coroas protéticas, clinicamente aceitáveis, apresentam desajustes da ordem de $60 \mu \mathrm{m}$ em média (JORGENSEN $\left.{ }^{5}, 1960\right)$ ), é imprescindivel que o agente cimentante preencha este espaço e apresente baixa ou nenhuma solubilidade, evitando a infiltração ao longo do tempo.

Este trabalho, no entanto, utilizou o cimento de fosfato de zinco como fator de comparação, porque é um cimento que vem sendo utilizado há décadas, e quando a prótese apresenta boa adaptação e permite uma boa higienização, não será este cimento que provocará o fracasso da prótese. WHITE et al. ${ }^{14}$ (1992) comentam que o sucesso histórico do cimento de fosfato de zinco pode resultar de propriedades ainda pouco pesquisadas, como a atividade antimicrobiana.

Além disso, um dos maiores inimigos dos cimentos resinosos é a dificuldade de controle da umidade, principalmente em preparos dentários intra-sulculares, e este é um fator inexistente nas pesquisas laboratoriais. Talvez, os agentes cimentantes de última geração provem sua superioridade em relação a determinadas propriedades, contudo, pesquisas clínicas longitudinais com estes novos materiais são necessárias, antes de se condenar o cimento de fosfato de zinco ao desuso.

\section{CONCLUSÃO}

De acordo com as condições experimentais deste trabalho, conclui-se que:

O cimento resinoso Panavia 21 apresenta melhores resultados quanto ao grau de infiltração quando comparado com o cimento de fosfato de zinco na cimentação de coroas metálicas fundidas.

\section{AGRADECIMENTOS}

Ao Departamento de Materiais Dentários da FOUSP. Ao CNPq, pela concessão da Bolsa de Iniciação Científica PIBIC-CNPq-USP.

CAMPOS, T. N.; MORI, M.; HENMI, A. T.; SAITO, T. Marginal microleakage of cast metal crowns luting agents. Rev Odontol Univ São Paulo, v. 13, n. 4, p. 357-362, out./dez. 1999.

One of the main goals of the luting agent, which bonds the cast restoration to the prepared tooth, is to seal the gap between them. Standardized preparations were made on 20 extracted teeth in order to evaluate microleakage. The crowns were made in $\mathrm{NiCr}$, and in one group of 10 crowns zinc phosphate was used as the luting agent; in the other 10, Panavia 21 was used. The samples were thermocycled and then put into methylene blue solution $(0.5 \%)$. After buccolingual sectioning of the cemented crowns, the samples were examined with a magnifier. There was a significant difference between the two groups: $100 \%$ of the zinc phosphate cemented crowns presented microleakage reaching the dentin and the pulp and $100 \%$ of the samples with Panavia 21 did not suffer any microleakage. So, as to the marginal microleakage with cast metal crowns in $\mathrm{NiCr}$, the Panavia 21 luting agent presented better results than did zinc phosphate.

UNITERMS: Dental leakage; Cementation; Crown.

\section{REFERÊNCIAS BIBLIOGRÁFICAS}

1. AMES, W. B. A new oxiphosphate for crown setting. Dent Cosmos, v. 34, n. 4, p. 392-393, Apr. 1892.

2. BOWEN, R. L.; RAPSON, J. E.; DICKSON, G. Hardening shrinkage and hidroscopic expansion of composite resins. J Dent Res, v. 61, n. 5, p. 654-658, May 1982.

3. GODOROVSKY, S.; ZIDAN, O. Retentive strength desintegration, and marginal quality of luting cements. $\mathbf{J}$ Prosth Dent, v. 68, n. 2, p. 269-274, Aug. 1992.
4. HEGDAHL, T.; GJERDET, N. R. Contraction stresses of composite resin filling materials. Acta Odontol Scand, v. 35, n. 4, p. 191-195, 1977.

5. JORGENSEN, K. D. Factors affecting the film thickness of zinc phosphate cements. Acta Odontol Scand, v. 18, n. 4, p. 479-490, 1960.

6. LEINFELDER, K. F.; LEMONS, J. E. Clinica restauradora - Materiais e Técnicas. São Paulo : Santos, 1989. p. $116-117$. 
CAMPOS, T. N.; MORI, M; HENMI, A. T.; SAITO, T. Infiltração marginal de agentes cimentantes em coroas metálicas fundidas. Rev Odontol Univ São Paulo, v. 13, n. 4, p. 357-362, out./dez. 1999.

7. OMURA, I. Adhesive and mechanical properties of a new dental adhesive. J Dent Res, v. 63, n. 3, p. 233, Mar. 1984.

8. OSBORNE, J. W . A method for assessing the clinical solubility and desintegration of luting cements. J Prosthet. Dent, v. 40, n. 4, p. 413-417, Oct. 1978.

9. SAITO, T. Preparos dentais funcionais em prótese fixa. São Paulo : Quintessence, 1989. 185 p.

10. STANINEC, M.; GILLES, W. S.; SARKU, J. M.; HATTORI, M. Caries penetration and cement thickness of three luting agents. Int J Prosthodont, v. 1, n. 3, p. 259-263, Nov./Dec. 1988
11. TJAN, A.H.L.; LI, T. Seating and retention of complete crowns with a new adhesive resin cement. J Prosthet Dent, v. 67, n. 4, p. 478-483, Apr. 1992.

12. TJAN, A. H. L.; DUNN, J. R.; GRANT, B. E. Marginal leakage of cast gold crowns luted with an adhesive resin cement. J Prosthet Dent, v. 67, n. 1, p. 11-15, Jan. 1992.

13. WHITE, S. N.; YU, Z.; TOM, J. F. M. D. In vivo microleakage of luting cements for cast crowns. J Prosthet Dent, v. 71, n. 4, p. 333-338, Apr. 1994.

14. WHITE, S. N.; SORENSEN, J. A.; KANG, S. K.; CAPUTO, A. A. Microleakage of new crown and fixed partial denture luting agents. J Prosthet Dent, v. 67, n. 2, p. 156-161, Feb. 1992.

Recebido para publicação em 29/01/99 Enviado para reformulação em 24/06/99 Aceito para publicação em 19/10/99 